\title{
Characterization Nanofillers from Agriculture Waste for Polymer Nanocomposites Reinforcement
}

\author{
Bastian Arifin ${ }^{1}$, Sri Aprilia ${ }^{1 *}$, Pocut Nurul Alam $^{1}$, Farid Mulana $^{1}$, Amri Amin ${ }^{2}$, Dilla Mars Anaska ${ }^{1}$, and Dwita Eka Putri ${ }^{1}$ \\ ${ }^{1}$ Chemical Engineering Department Engineering Faculty, University of Syiah Kuala, Banda Aceh, 23111, Indonesia \\ ${ }^{2}$ Mechanical Engineering Department, Engineering Faculty, University of Abulyatama, Lampoh Keude, Aceh Besar, Indonesia
}

\begin{abstract}
The current development of the packaging industry is increasing as well as the dependence of non-renewable oil-based materials encouraging researchers to look for alternative polymeric strengthening materials from biomass. Especially used from agricultural waste because it is cheap and widely available in nature and it can be renewed. In this study, agriculture waste used were rice husk and rice husks ash that prepared as organic nanofillers for the development of polymer nanocomposites. XRF analysis showed that rice husk ash has the highest silica $\left(\mathrm{SiO}_{2}\right)$ content of $89.835 \%$, while rice husk has $\mathrm{SiO}_{2}$ contents of $82.540 \%$. From XRD analysis on 2 theta there is a crystalline silica region at $22^{\circ}$ and this analysis shows the sample is amorphous. FTIR analysis showed Si-H at peak $2339 \mathrm{~cm}^{-1}$ in rice husk and $2129 \mathrm{~cm}^{-1}$ for rice husk ash.
\end{abstract}

\section{Introduction}

The development of bionanocomposite materials has attracted much attention from scientists, researchers and industries, especially to obtain environmentally friendly materials and the use of materials for tomorrow's sustainability $[1,2]$. The addition of this nanofiller aims to improve good performance on bionanocomposite materials in various application areas such as: automotiv, construction, electronics and packaging as well, because they have low density, good stiffness, good thermal and mechanical properties $[3,4]$. The use of nanofillers as reinforcement in composite polymers has many advantages such as low cost, renewable natural resources, special properties, low density, easy preperation, require low energy for process, biodegradable, widespread and relatively non-abrasive use compared to strengthening with traditional materials $[5,6]$.

Research on the utilization of rice straw and rice husk in Indonesia is still very limited. These waste is used only as animal feed and energy or fuel or as adsorption on heavy metals [7]. While the utilization of polymer technology is still very rarely reported. Silica $\left(\mathrm{SiO}_{2}\right)$ is a basic raw material that can be used to strengthen matrix polymers and is usually used in polymeric industries for electronics, ceramics. Many silica applications can be used in technology applications because silica starch particles have properties as tixotropic agents, thermal insulators, and composite fillers [8]. Silica-based manufacturing products have high strength at high temperatures. Because of this nature, the wastes of rice can be added to the matrix polymer as a bionanofiler and also as an alternative solution to environmental problems, thereby increasing the added value in agricultural waste.

Research has been done using rice husk and rice husk ash. Characterization of both samples has been done to determine the silica content by using X-ray fluorescence (XRF) spectra, fourier transform infrared (FTIR) and $\mathrm{X}$-ray diffraction (XRD) analysis.

\section{Materials and methods}

Rice husk is light yellow colour fiber. The fiber was ground up from Aceh Province, Indonesia. Rice husk ash was got from the burning of rice husk. The samples were collected from rice plant Aceh Besar, Indonesia.

Rice husk and rice husk ash were washed and dried in an oven overnight. The dried samples were chopped by blender and smoothed using ball mill for $12 \mathrm{~h}$ and then screnning with a 325 mesh.

\subsection{XRF analysis}

$\mathrm{X}$-ray fluorescence (XRF) spectrometer was used for measured the purity of silica by a PANalytical AXIOS. The silica content of surface area was measured on a TriStar II 3020. The samples for surface area measurement were dried at $250{ }^{\circ} \mathrm{C}$ over $8 \mathrm{~h}$ prior to the measurement.

\subsection{FTIR analysis}

Fourier transform infrared (FTIR) spectrocopy analysis has used to employed of characterization of the silica

\footnotetext{
*Corresponding author: sriaprilia@,unsyiah.ac.id
} 
content in absorption spectra to get information the organic structure. The analysis was used by using a FTIR spectroscopy (Shimadzu FTIR Spectrometer). The sample was analyzed into the Nicolet Avatar for FTIR Spectrometer. The analyisi of spectra were recorded in the range of wave length about $4000-400 \mathrm{~cm}^{-1}$.

\subsection{XRD analysis}

Analysis of X-Ray diffraction were purposed to determine the crystallinity index and crystal size of samples. XRD analyses were on an X-Ray diffractometer with measurement condition are $40 \mathrm{kV}$ and current $30 \mathrm{~mA}$. The scattering angle range (20) was from $10^{\circ}$ to $80^{\circ}$ with the scan rate of $10^{\circ} / \mathrm{min}$.

\subsection{Particle size analyzer}

Malven Instruments was used for analysis of distribution of particle size on rize husk and rize husk ash. The instrument of Malven with the long Benc Mastersizer S and fitted with the Qspec Dry Powder Feeder. This analysis, the sample weighted in (two) 2 grams. The number of distribution at $10 \%, 50 \%$ and $90 \%$ cut-off point was done with well as the number of mean diameter.

\section{Result and disscussion}

\subsection{Chemical compounds}

From XRF analysis used for chemical compounds of the rice husk and rice husk ask. The elemental components of rice husk and rice husk ash come in the form of chemical compounds. Chemical compounds of silica in the sample rice husk and rice husk ask shown in Table 1. Silica content in the form of bulk $\mathrm{SiO}_{2}$. In addition to silica as the main component, many other components exist in the sample.

From Table 1 it can be seen that there are $\mathrm{Na}_{2} \mathrm{O}$, $\mathrm{MgO}, \mathrm{Al}_{2} \mathrm{O}_{3}, \mathrm{P}_{2} \mathrm{O}_{5}, \mathrm{SO}_{3}, \mathrm{~K}_{2} \mathrm{O}, \mathrm{CaO}, \mathrm{MnO}, \mathrm{Fe}_{2} \mathrm{O}_{3}$ and SrO contents. The $\mathrm{SiO}_{2}$ as a main chemical composition. The silica content $\left(\mathrm{SiO}_{2}\right)$ in rice husk ash is higher than the rice husks, $89.835 \%$ and $82.540 \%$, respectively. The other compounds for the rice husk ask low, it is show that after burning of rice husk, all impurities remove. Liu et al, 2013 [9] has mentioned that removing organic matter occured only heat at moderate temperatures to avoid the fusion of the $\mathrm{SiO}_{2}$ product. In biological system, the six metals common come such as $\mathrm{Na}, \mathrm{Mg}, \mathrm{Al}$, $\mathrm{K}, \mathrm{Ca}$, and $\mathrm{Fe}$, and also $\mathrm{Si}$, were detected simultaneously with the mass spectrometer.

\subsection{Functional group}

FTIR analysis for rice husk and rice husk ash are show in Fig. 1 and 2. From Fig. 1 and 2 shows that many chemical compounds found with FTIR analysis. The stretching area is seen at $3266 \mathrm{~cm}^{-1}$ and $2895 \mathrm{~cm}^{-1}$ peaks for rice husk and $3207 \mathrm{~cm}^{-1}$ and $2837 \mathrm{~cm}^{-1}$ for rice husk ash. At the peak of about $3200 \mathrm{~cm}^{-1}$ there is an $\mathrm{O}-\mathrm{H}$ stretching hydrogen bond. The hydrophilic area was absorbed at $3100-3700 \mathrm{~cm}^{-1}$, this area being a group of $-\mathrm{OH}$ in aliphatic compounds or aromatic alcohols. The peak around $2929 \mathrm{~cm}^{-1}$ is due to stretching C-H from compounds of aliphatic saturated. The two peaks of this stretch correspond to the aliphatic parts in cellulose and hemicellulose. In the triple bond region, the peaks are at $2351 \mathrm{~cm}^{-1}$ and $2142 \mathrm{~cm}^{-1}$. At peak $2351 \mathrm{~cm}^{-1}$ is expressed as P-H stretching and $\mathrm{P}-\mathrm{O}-\mathrm{H}$ stretching. At the peaks around $2129 \mathrm{~cm}^{-1}$ shown as $\mathrm{Si}-\mathrm{H}$ stretching. It can be deduced that the wave length in this region represent multivalent inorganic hydrides or oxides. The $\mathrm{C}=\mathrm{O}$ strectch at the double bonding region at $1723 \mathrm{~cm}^{-1}$ in both spectra is assigned as acetyl and uronic ester.

Table 1. Chemical compositions

\begin{tabular}{ccc}
\hline $\begin{array}{c}\text { Chemical } \\
\text { compounds }\end{array}$ & Rice husk (\%) & $\begin{array}{c}\text { Rice husk ash } \\
(\%)\end{array}$ \\
\hline $\mathrm{Na}_{2} \mathrm{O}$ & 0.254 & 0.268 \\
$\mathrm{MgO}$ & 1.055 & 1.734 \\
$\mathrm{Al}_{2} \mathrm{O}_{3}$ & 0.174 & 0.446 \\
$\mathrm{SiO}_{2}$ & 82,540 & 89.835 \\
$\mathrm{P}_{2} \mathrm{O}_{5}$ & 0.501 & 0.661 \\
$\mathrm{SO}_{3}$ & 0.314 & 0.213 \\
$\mathrm{~K}_{2} \mathrm{O}$ & 1.115 & 3.490 \\
$\mathrm{CaO}$ & 1.509 & 1.498 \\
$\mathrm{MnO}$ & 1.490 & 0.512 \\
$\mathrm{Fe} \mathrm{O}_{3}$ & 11.019 & 1.330 \\
$\mathrm{SrO}$ & 0.028 & 0.012 \\
\hline
\end{tabular}

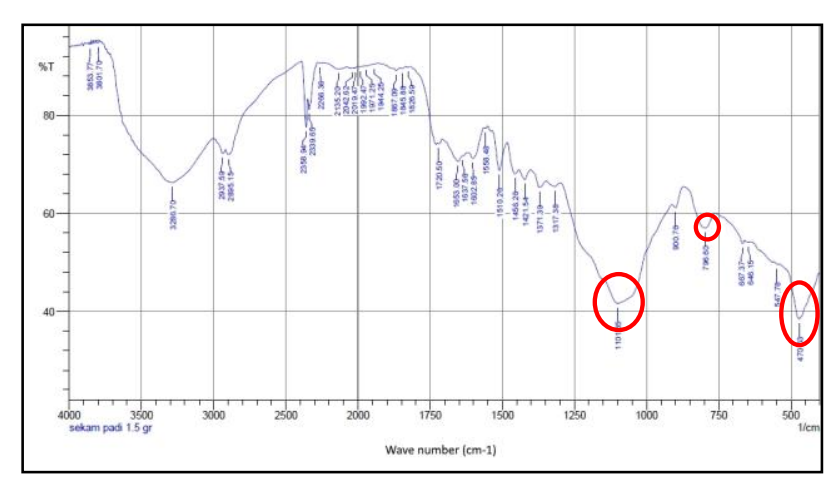

Fig. 1. FTIR of the rice husk

Amide is shown at the peak $1643 \mathrm{~cm}^{-1}$ for rice husk and $1649 \mathrm{~cm}^{-1}$ for rice husk ash. The amide peak I presents $80 \%$ of $\mathrm{C}=\mathrm{O}$ stretching at the amide group, connected with $\mathrm{N}-\mathrm{H}$ bending and $\mathrm{C}-\mathrm{N}$ stretching. In the secondary structure of protein, the vibration depends on the nature of the hydrogen bonds involved in the $\mathrm{C}=\mathrm{O}$ and $\mathrm{N}-\mathrm{H}$ groups. In the area of fingerprint, there are many sharp peaks coul be shown from both of spectra. At the range $1450-1370 \mathrm{~cm}^{-1}$ of the symmetrical C-H and 
asymmetric deformation. The area sircle red at 1101, 795 and $470 \mathrm{~cm}^{-1}$ for rice husk and 1103, 802 and $466 \mathrm{~cm}^{-1}$ for rice husk ash are due to the symmetric, asymmetric, and bending modes of $\mathrm{SiO}_{2}$, respectively.

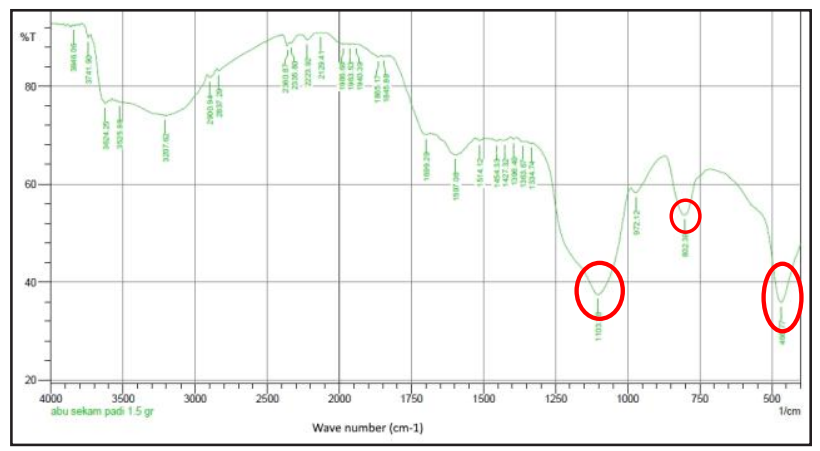

Fig. 2. FTIR of the rice husk ash

\subsection{Crystallinity region}

The XRD patterns of silica sample from rice husk and rice husk ash shown in Fig. 3. The two patterns are close to each others, where both are seen crystalline silica peak at 2 theta at $22^{\circ}$. The peak of the crystalline silica is consistent with the results, it was shown by Le et al., 2013 [10]. Chen et al., 2013 [11] in his research stated that the same two sample patterns show that both samples are amorpous.

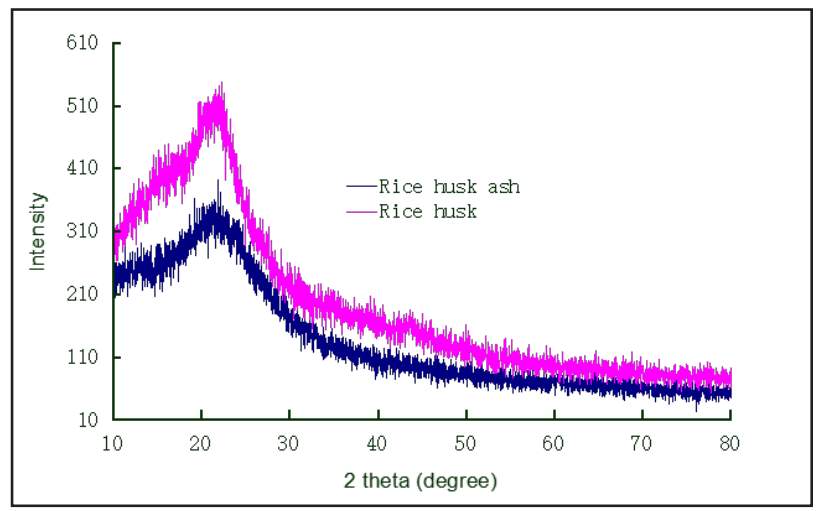

Fig. 3. XRD patern of rice husk and rice husk ash

Depend on Saceda and Leon, 2011 [12], that the received rice husk ash have defined Bragg's peaks at $2 \theta$ value of $21.9^{\circ}$ and several distinct peaks at 20.9, 26.6 and $36.0^{\circ}$.

\subsection{Particle size}

The particles size distribution of rice husk and rice husk ash particles has been marked of the base and the level of aggregation and agglomeration form. The used of Malven Mastersizer S Analyzer to predicted particle size and distribution analysis. The results obtained are shown in Fig. 4 and Fig. 5. The range of distribution carbonized particle from rice husk and rice husk ash after sieve pass 325 mesh.. The size of particulate silica at pass trought 325 mesh show in size of distribution range is below $45.06 \mu \mathrm{m}$. Particle size of rice husk and rice husk ash in the size of distribution particle shown that in the range because it has come form aglomeration of particles.

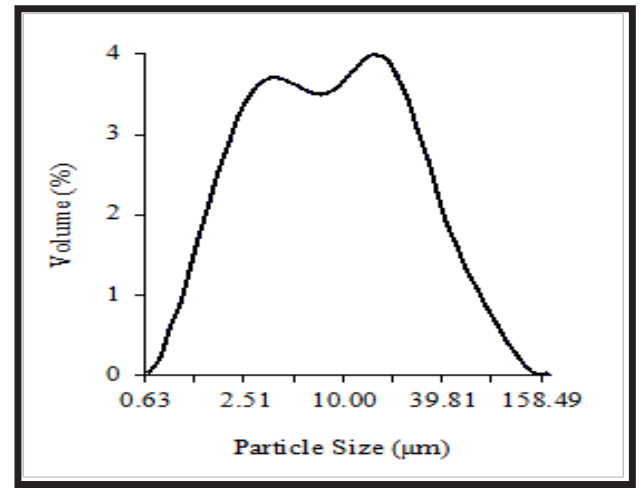

Fig. 4. Particles size of rize husk

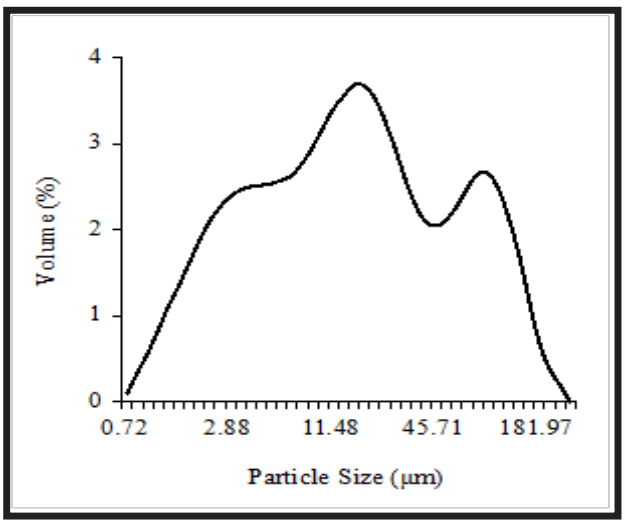

Fig. 5. Particle size rice husk ash

\section{Conclusion}

Rice husk and rice husk ash have successfully performed characteristics. Bionano filler from rice husk and rice husk ash has been done by passing the particles on the screening of 325 mesh about $<45 \mu \mathrm{m}$. The largest silica content is obtained on rice husk ash. $\mathrm{Si}-\mathrm{H}$ is present at the peak of $2339 \mathrm{~cm}-1$ in rice husk and $2129 \mathrm{~cm}-1$ for rice husk ash. From the XRD analysis for both samples of crystalline silica there are at 2 theta 22 degrees and both samples are in the amophouse.

Acknowledgment: The authors would like to thank the Institute for Research and Community Service Unsyiah and Directorate of Research and Community Service and Directorate General of Research and Development, Ministry of Research, Technology and Higher Education who have funded this research in accordance with the Research Contract No. 105/ SP2H / LT / DPRM / IV /2017, April 03, 2017.

\section{References}

1. H.P.S. Abdul Khalil, Rus Mahayuni A.R., Irsyad-ul-haq Bhat, Rudi, D., Almulali, M.Z. and Abdullah, C.K., Bioresources, 7, 5771-5780 (2012).

2. H.P.S. Abdul Khalil, N.A.Sri Aprilia, Bhat, A.H., Jawaid, M., Paridah, M.T., Dungani, R, Renewable and Sustainable Energy Rev. 22, 667-685 (2013)

3. N.A. Sri Aprilia, H.P.S. Abdul Khalil, A.H. Bhat, R. Dungani, Hossain, Md.S., Bioresources, 9 (3), 
4888-4898 (2014).

4. K. Majeed, M. Jawaid, and A. Hassan, Abu Bakar, A., Abdul Khalil, H.P.S., Salema, A.A., Inuwa, I., Mater. Des., 46, 391-410 (2013).

5. K.S. Kim,H. Choi, S.-W., Lee,B.-H., Kim,S., Kim, H.-J., Cho C. W. and Cho, D., J. Therm. Anal. Calorim., 89 (3), 821-82 (2007)

6. T. Mekonnen, Mussone, P., Alemaskin, K., Sopkow, L., Wolodko, J., Choi, P. and Bressler, D., J. Mater. Chem. A, 1, 13186-13196 (20013).

7. N.S. Awwad, Gad, H.M.H, Ahmad, M.I., Aly, H.F., Biointerfaces 81, 593-599 (2010)

8. V.B. Carmona, Oliveira, R.M., Silva, W.T.L., Mattoso, L.H.C., Marconcini, J.M., Ind. Crops Prod. 43, 291- 296 (2013).

9. X. Liu, X.dong Chen, L. Yang, H. Chen, Y. Tian, Z. Wang 2016, Res. Chem. Intermed. 42 (2), 893-913 (2016)

10. V. H. Le, C. N. H. Thuc and H.H. Thuc, Nanoscale Research Letters, 1-10 (2013)

11. H. Chen, W. Wang, J. C. Martin, A. J. Oliphant, P. A Doerr, Jeffery F. Xu, Katelyn M. DeBorn, Caixing Chen, and Luyi Sun, ACS Sustainable Chem. Eng. 1, 254-259 (2013).

12. J-J. F. Saceda and R.L. De Leon, Quim. Nova, 34,1394-1397 (2011) 